\title{
Effects of Different Shoe Heel Heights on the Kinematic Variables of the Lower Extremities during Walking on Slopes by healthy adult women
}

\author{
Yong-pil Yang, PT, $\mathrm{PhD}^{\dagger}$ \\ Department of Physical Therapy, Dongshin University
}

Received: April 30, 2019 / Revised: May 2, 2019 / Accepted: May 30, 2019

(C) 2019 J Korean Soc Phys Med

\section{| Abstract |}

PURPOSE: This study examined the changes in the kinematic variables during walking on a downhill ramp according to the shoe heel height.

METHODS: The subjects were 10 adult women with no history of musculoskeletal disorders who agreed to participate in the study. Data were collected using a motion analysis system (VICON) consisting of six infrared cameras. The slope was $120 \mathrm{~cm}$ in width, $200 \mathrm{~cm}$ in length, and 15 出 in inclination. To confirm the change in gait parameters (stride length, gait speed) and lower extremity joint angle according to the heel heights of the shoes, flat, $5 \mathrm{~cm}$, and $10 \mathrm{~cm}$ heel shoes were prepared and walked alternately.

RESULTS: As a result, both the stride length and walking speed showed significant differences according to the heel height between flat and $10 \mathrm{~cm}(\mathrm{p}<.05)$. In the sagittal plane, there was no significant difference in the hip joint and knee joint, but a significant difference was observed in all events in the ankle joint on all heel heights $(p<.05)$. In particular, the

†Corresponding Author: Yong-pil Yang raonpt@dsu.ac.kr, http://orcid.org/0000-0002-9398-623X

This is an Open Access article distributed under the terms of the Creative Commons Attribution Non-Commercial License (http://creativecommons.org/licenses/by-nc/3.0) which permits unrestricted non-commercial use, distribution, and reproduction in any medium, provided the original work is properly cited. heel strike and mid stance events showed significant differences among all height conditions $(\mathrm{p}<.05)$. No significant difference was observed in any of the joint angle changes in the frontal plane ( $\mathrm{p}>05)$.

CONCLUSION: As the shoe heel height increased, the instability increased and efforts to secure the stability were made, leading to a shortened stride length, walking speed, and angle of the ankle joint.

Key Words: Analysis, Gait, Shoe heel

\section{Introduction}

Sales of high-heel shoes have increased with modern social activities and business attire. This trend has increased the time women spend walking in high-heeled shoes [1]. High heels contribute to aesthetic appeal, but the negative side effects from wearing high heels are on the rise. Footwear is one of the main factors affecting the walking characteristics, and with the heels directly contacting the ground, is closely related to injuries and can alter the kinematics [2]. An additional concern is the varying terrain that may be encountered while wearing high-heeled shoes: unleveled surfaces, stairs, ramps, etc. Wearing high heels over these types of terrain can lead to a range of changes in the kinematic characteristics [3]. While the risk of falls when walking on a ramp is less than that when walking 
on stairs, there is still a risk of falling due to slipping or loss of balance when walking downhill [2].

McIntosh et al. [4] reported that the greater the downward slope, the larger the stride length and walking speed. In terms of the joint angle, the greater the slope, the greater the hip joint angle when the heel is in contact with the ground. McVay and Redfern [5] suggested that slipping on ramps is a potential problem because the shearing force increases when the slope increases. Slipping caused by a sudden change in walking environment, such as the slope, 0 . is a major cause of injuries in everyday environments [6,7]. When these walking conditions are repeated, it places additional strain on the body. Therefore, it is very important to observe and analyze the changes in walking characteristics due to ramp slopes.

Recently, studies on the changes in walking kinematics variables and sports biomechanics have been conducted because of the development of motion capture equipment $[3,6,8,9]$. On the other hand, few studies have examined the behavior in high heels when walking on ramps, which are encountered frequently. This study analyzed the changes in kinematic variables during downhill walking with varying heel heights to provide basic data that can be useful for related future studies. A difference between the walking parameters and the lower extremity angle according to the shoe heel height on the downhill ramp was anticipated.

\section{Research Method}

\section{Subjects}

The average age of the 10 female D university students was 20.5 years. The subjects had not had a musculoskeletal disorder or injury within the last year, and volunteered for the study. All subjects gave consent to participate in the study after being instructed about the purpose and method of the experiment prior to starting the study. Table 1 lists the characteristics of the subjects.
Table 1. General Characteristics of Subjects

\begin{tabular}{cc}
\hline & $\mathrm{N}=10$ \\
\hline Age (yrs.) & $20.556 \pm .726^{\mathrm{a}}$ \\
Weight & $52.433 \pm 4.217$ \\
Height & $161.733 \pm 3.935$ \\
Shoe size & $237.222 \pm 70.120$ \\
\hline
\end{tabular}

${ }^{\mathrm{a}}:$ mean $\pm \mathrm{SD}$

\section{Research Instruments and Measurement Procedure}

\section{1) Data Collection}

The kinematic data were collected using a motion analysis system (VICON MX-F20, Oxford Metrics Ltd, Oxford, UK) consisting of six infrared cameras installed in the H-university motion analysis room at $120 \mathrm{~Hz}$. A Woltering filtering method was used to filter the data and the mean squared error (MSE) was set to 15. Static and dynamic calibrations were conducted prior to capturing the walking movement. The subjects' height; widths of the elbows, shoulders, wrists, knees, and ankles joints; and leg lengths were measured to obtain the center of rotation of the human joints. The plug-in gait marker set was used and $14-\mathrm{mm}$ spherical reflective markers were attached to the left and right lower limbs of the subjects with double-sided tape. Retroreflective markers, 16 in total, were attached to the anatomical boundary points: the superior iliac spine, sacrum, lateral mid-thigh, lateral epicondyle, lateral mid shank, lateral malleolus, heels, and toes (Fig. 1) [9].

\section{2) Slope}

Referring to previous studies utilizing a sloping surface [10,11], a ramp was constructed with a width of $120 \mathrm{~cm}$, a slope length of $200 \mathrm{~cm}$, and a slope angle of $15^{\circ}$. Slip - resistant tape was attached to the ramp to minimize the influence of the slip - induced walking parameters (Fig. 2).

\section{Measurement Procedure}

To identify the change in walking by varying the heel 

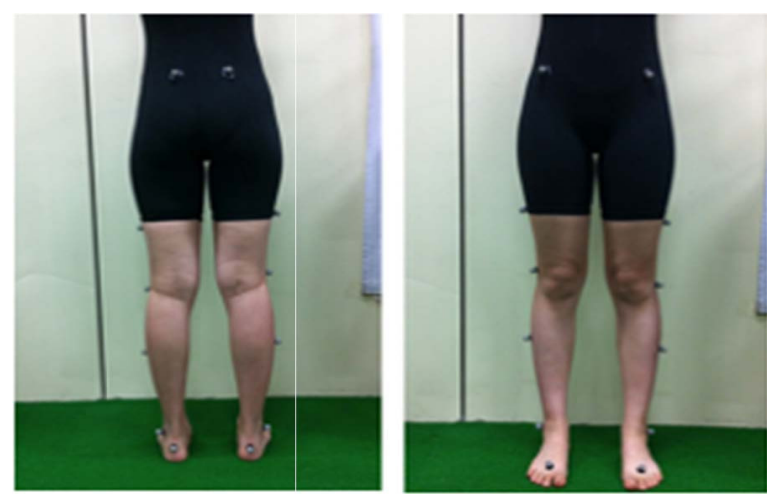

Fig. 1. Maker's attachment point

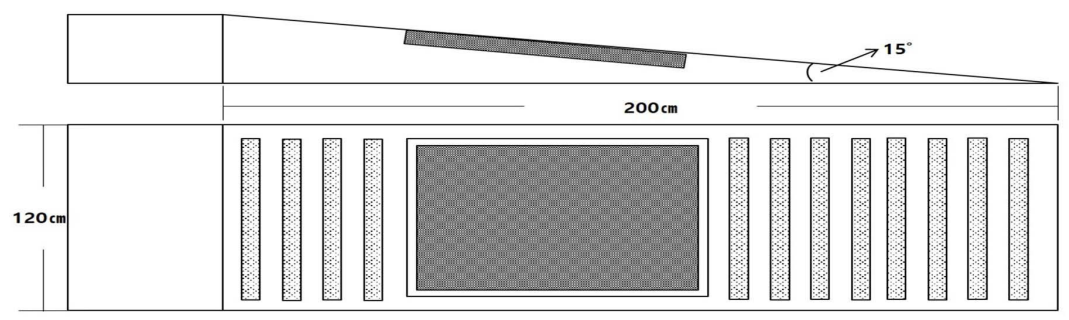

Fig. 2. Structure of the slope

heights, the subjects walked on a slope under three shoe conditions: without heels (flats), $5 \mathrm{~cm}$ heels, and $10 \mathrm{~cm}$ heels. According to the shoe heights, shoes were selected according to their shoe size and adjusted for 10 minutes to allow for natural walking. In addition, the subjects wore simple and comfortable clothing that would not impede their movements or obscure the markers while moving. Before the measurements, the subjects walked back and forth on the slope to familiarize themselves with the ramp. The walking cycle was set to $100 \%$ from the heel strike to the next heel strike of the same foot based on the right foot. In addition, to examine the difference in the movements of the lower limb joints in the walking pattern during the stance phase, the movement timing was classified further into the mid stance, heel off, and toe off [12]. The average of three sets of data was used, which were judged to be accurate after five measurements with sufficient practice time to adapt to the shoe.

\section{Analysis Method}

All analyses were conducted using SPSS for Windows (ver. 22.0; IBM Corp., Armonk, NY, USA). In this study, the dependent variables were the gait variable and lower extremity angle. In addition, the independent variable was the shoe heel height. The mean and standard deviation of the gait variables and lower extremity angles were calculated. One-way ANOVA with a Bonferroni's correction was used to determine the difference among the shoe heel heights. The difference was considered significant at the $\alpha=.05$ level.

\section{Results}

\section{Changes in the walking variables}

When the subjects walked on the downhill slope, the stride length and walking speed showed a significant difference according to the heel height $(\mathrm{p}<.05)$, particularly 
Table 2. Difference in the Gait Variables According to the Shoe Heel Height

\begin{tabular}{ccccc}
\hline Gait Variable & Flat & $5 \mathrm{~cm}$ & $10 \mathrm{~cm}$ & $p$ \\
\hline Stride Length $(\mathrm{m})$ & $1.115 \pm .061^{\mathrm{a}}$ & $1.063 \pm .067$ & $.969 \pm .063$ & $.002^{\text {tł }}$ \\
Gait Speed $(\mathrm{m} / \mathrm{s})$ & $1.131 \pm .138$ & $1.043 \pm .128$ & $.915 \pm .142$ & $.026^{\dagger}$ \\
\hline
\end{tabular}

${ }^{\mathrm{a}}:$ mean $\pm \mathrm{SD}$

$\dagger$ : significant difference between flat and $10 \mathrm{~cm}(\mathrm{p}<.05)$

₹: significant difference between $5 \mathrm{~cm}$ and $10 \mathrm{~cm}(\mathrm{p}<.05)$

Table 3. Difference in the Kinematic Variables According to the Shoe Heel Height on the Sagittal Plane

\begin{tabular}{|c|c|c|c|c|c|c|}
\hline & & Joint & Flat & $5 \mathrm{~cm}$ & $10 \mathrm{~cm}$ & $\mathrm{p}$ \\
\hline \multirow{12}{*}{$\begin{array}{c}\text { Sagittal } \\
\text { Plane } \\
\left({ }^{\circ}\right)\end{array}$} & \multirow{3}{*}{ Heel Strike } & Hip & $18.833 \pm 5.862^{\mathrm{a}}$ & $22.414 \pm 10.636$ & $17.989 \pm 4.645$ & .516 \\
\hline & & Knee & $7.273 \pm 4.979$ & $11.073 \pm 7.132$ & $1.920 \pm 5.993$ & .435 \\
\hline & & Ankle & $-12.533 \pm 6.405$ & $-23.450 \pm 9.208$ & $-33.344 \pm 4.066$ & $.000^{*+\neq}$ \\
\hline & \multirow{3}{*}{ Mid Stance } & Hip & $4.173 \pm 4.471$ & $5.189 \pm 3.896$ & $3.887 \pm 2.983$ & .802 \\
\hline & & Knee & $14.683 \pm 7.599$ & $13.242 \pm 5.921$ & $13.511 \pm 5.078$ & .902 \\
\hline & & Ankle & $7.591 \pm 4.621$ & $-10.081 \pm 8.413$ & $-20.689 \pm 4.041$ & $.000^{*+\neq}$ \\
\hline & \multirow{3}{*}{ Heel Off } & Hip & $3.287 \pm 3.084$ & $-.446 \pm 8.906$ & $.886 \pm 5.769$ & .551 \\
\hline & & Knee & $14.682 \pm 7.599$ & $13.243 \pm 5.922$ & $13.511 \pm 5.078$ & .902 \\
\hline & & Ankle & $7.591 \pm 4.621$ & $-10.081 \pm 8.413$ & $-20.689 \pm 4.041$ & $.000^{*+\ddagger}$ \\
\hline & \multirow{3}{*}{ Toe Off } & Hip & $-14.040 \pm 4.583$ & $-14.369 \pm 4.508$ & $-13.327 \pm 2.511$ & .883 \\
\hline & & Knee & $22.161 \pm 4.411$ & $18.597 \pm 9.801$ & $21.101 \pm 4.572$ & .606 \\
\hline & & Ankle & $17.981 \pm 5.189$ & $.396 \pm 6.349$ & $-6.179 \pm 4.462$ & $.000^{* \dagger}$ \\
\hline
\end{tabular}

${ }^{\mathrm{a}}:$ mean $\pm \mathrm{SD}$

* : significant difference between flat and $10 \mathrm{~cm}(\mathrm{p}<.05)$

$\dagger$ : significant difference between flat and $5 \mathrm{~cm}(\mathrm{p}<.05)$

₹ : significant difference between $5 \mathrm{~cm}$ and $10 \mathrm{~cm}(\mathrm{p}<.05)$

between the flat and $10 \mathrm{~cm}$ heel condition $(\mathrm{p}<.05)$. The stride length and walking speed decreased $10 \mathrm{~cm}$ more than the flat $(\mathrm{p}<.05)($ Table 2$)$.

\section{Changes in the lower limb sagittal joint angles (flexion and extension)}

The hip and knee joints did not show a significant difference at the time of the heel strike, mid stance, heel off, or toe off. On the other hand, there was a significant difference at all time points in the ankle joint for all conditions, particularly at the heel strike and mid stance $(\mathrm{p}<.05)$. At the heel strike and toe off points, however, there was a significant difference only between the flat and $5 \mathrm{~cm}$ heel and between the flat and $10 \mathrm{~cm}$ heel conditions $(\mathrm{p}<.05)$ (Table 3). In the ankle joint, the plantar flexion tended to increase with increasing shoe heel height.

3. Changes in the lower limb frontal joint angles (abduction and adduction)

No significant differences in the frontal joint kinematics for any joint due to the different heels were observed (Table 4). 
Table 4. Difference in the Kinematic Variables According to the Shoe Heel Height on the Frontal Plane

\begin{tabular}{|c|c|c|c|c|c|c|}
\hline & & Joint & Flat & $5 \mathrm{~cm}$ & $10 \mathrm{~cm}$ & $p$ \\
\hline \multirow{12}{*}{$\begin{array}{c}\text { Frontal } \\
\text { Plane } \\
\left({ }^{\circ}\right)\end{array}$} & \multirow{3}{*}{ Heel Strike } & Hip & $-.583 \pm 1.915^{\mathrm{a}}$ & $.306 \pm 5.421$ & $-1.540 \pm 3.376$ & .675 \\
\hline & & Knee & $4.166 \pm 2.291$ & $5.957 \pm 6.493$ & $5.830 \pm 2.376$ & .679 \\
\hline & & Ankle & $.623 \pm 2.457$ & $1.254 \pm 2.401$ & $-.043 \pm 2.056$ & .586 \\
\hline & \multirow{3}{*}{ Mid Stance } & Hip & $6.323 \pm 3.198$ & $4.627 \pm 2.784$ & $2.740 \pm 3.346$ & .128 \\
\hline & & Knee & $6.481 \pm 4.316$ & $6.891 \pm 3.611$ & $9.994 \pm 6.454$ & .368 \\
\hline & & Ankle & $2.011 \pm 2.580$ & $1.424 \pm 3.061$ & $.456 \pm 3.291$ & .631 \\
\hline & \multirow{3}{*}{ Heel Off } & Hip & $6.249 \pm 3.095$ & $-.446 \pm 8.906$ & $.886 \pm 5.769$ & .080 \\
\hline & & Knee & $6.481 \pm 4.316$ & $6.891 \pm 3.611$ & $9.994 \pm 6.454$ & .368 \\
\hline & & Ankle & $2.011 \pm 2.580$ & $1.424 \pm 3.161$ & $.456 \pm 3.291$ & .631 \\
\hline & \multirow{3}{*}{ Toe Off } & Hip & $4.927 \pm 3.077$ & $4.153 \pm 3.237$ & $3.370 \pm 2.211$ & .607 \\
\hline & & Knee & $7.623 \pm 7.318$ & $6.057 \pm 8.644$ & $9.732 \pm 10.048$ & .736 \\
\hline & & Ankle & $1.677 \pm 2.501$ & $1.073 \pm 2.568$ & $.369 \pm 4.519$ & .766 \\
\hline
\end{tabular}

${ }^{\mathrm{a}}$ : mean $\pm \mathrm{SD}$

\section{Discussion}

This study examined the changes in the gait parameters and the change in the lower extremity angle by three dimensional motion analysis.

The subjects walked down a ramp at varied heel heights (flat, $5 \mathrm{~cm}$, and $10 \mathrm{~cm}$ ). In previous studies, where the walking kinematics were investigated when walking on a slope, the step lengths tended to decrease with increasing angle of walking in the ascending and descending slopes $[11,13]$. In addition, in the same study, the change in angle increased with increasing slope at $3,6,9$, and $12^{\circ}$. In particular, the decrease in step length was remarkable [13]. This is similar to the results of the present study, in which the stride length decreased significantly with the heel heights while walking downhill on a ramp with high-heeled shoes. In addition, the slope of this study was similar to that of the previous study in terms of the result of walking at a larger angle than the previous study at $15^{\circ}$. These results suggest that the heel heights and conditions of the ground on walking have a direct impact on the walking variables, such as the step length. Both the slope and heel heights can affect the change in the step length but in the present study, the slope angle was maintained and the heel heights were varied. The step length decreased with increasing heel heights, which was attributed to a decrease in stability during the support phase.

In addition, when walking down a slope, the walking speed decreased with increasing heel heights. In particular, post hoc analysis revealed a significant decrease when walking in flat shoes compared to walking in shoes with $10 \mathrm{~cm}$ heel heights. When the heels become higher, the body center of mass is moved higher and the need for stability during walking increases $[3,10]$. In addition, the amount of contact between the shoes and the supporting surface is reduced, leading to changes in the temporal variables of walking $[14,15]$. Hence, the walking speed decreases with increasing heel height when walking downhill. In a related study, a close correlation was reported between the movement of the body center and movement of the lower limb in walking. Gravity has a direct effect on the walking speed in the movement accompanied by vertical movement [16]. Therefore, it appears that the stride length and walking speed are decreased as a result. 
This study also examined the angle changes of the lower extremity joints in the sagittal and frontal planes according to the heel heights at heel strike, mid stance, heel off, and toe off during downhill walking. First, in the sagittal plane, the flexion angle and extension angles did not show any significant difference at heel strike, mid stance, heel off, or toe off due to the varied heel heights at the hip joint and knee joint. At the ankle joint, however, a significant difference with varied heel heights was observed in all events. Post hoc analysis to verify the difference between different height conditions revealed a significant difference between flat and $5 \mathrm{~cm}, 5 \mathrm{~cm}$ and $10 \mathrm{~cm}$, and flat and $10 \mathrm{~cm}$ conditions. The plantar flexion increased with increasing heel heights and showed a significant difference in the comparison between each different heel heights at all events.

Sussman and D'amico [17] reported that for the ankle joints, plantar flexion increased with increasing heel height, leading to excessive load being concentrated on the front of the foot. This altered the bone position and affected the movement of the ankle joints and the angle of insertion of the associated muscles. For this reason, repeated walking with high-heeled shoes will cause an unusual load on the anterior aspect or toe of the foot. This can increase the possibility of deformation and damage to the toe joints.

Previous studies have shown that walking with heel shoe heights can affect the normal daily life due to deformations of the tendons, ligaments, and muscles because of the insufficient angular changes in the lower limbs [18]. Therefore, high-heeled walking resulted in a lack of dorsiflexion movement, which in turn could lead to problems of the ankle joint ligament, ligament, and muscle groups.

The frontal plane had no significant effects on any joints at any of the time events. On the other hand, the angle of the hip joint showed a tendency to abduct with increasing heel height, which is similar to that reported by Eun [19]. The abduction angle of the hip joint increased in most of the walking cycle when walking downhill. This may be due to the efforts to expand the base of support abducting the hips to compensate for the reduced body stability when walking downhill in high-heeled shoes.

This research had some limitations. The study was conducted on healthy individuals, making it difficult to generalize these results. Although the standardized high heel was applied, it appeared to have affected walking because of personal inconvenience. In future studies, it would be necessary to complement these points and identify the kinematic variables together to determine the coordination and load of the lower limb joints.

\section{Conclusion}

This study examined the kinematic changes when walking on a downhill ramp in high-heeled shoes with a varied heel heights (flat, $5 \mathrm{~cm}$, and $10 \mathrm{~cm}$ ). As a result, there were significant effects on the movement of the ankle joints in the sagittal plane. This verified the heel height as a major factor greatly influencing the movements at the ankle joints. The angle of the ankle joint changed significantly compared to a standard gait pattern. This resulted in additional requirements for unnecessary movements, reduced energy efficiency, and reduced stability during walking. Therefore, in future studies, it will be necessary to examine not only the difference in heel height, but also the energy consumption and stability of the lower extremities.

\section{Acknowledgements}

This study was supported by the Dongshin University research grants.

\section{References}

[1] Tim L, Doyle M, Zack R. Balance Suffers for high-heeled 
Fashion. Biomechanics. 2004.

[2] Cronin NJ. The effects of high heeled shoes on female gait: a review. J Electromyogr Kinesiol. 2014;24(2): $258-63$.

[3] Lay AN, Hass CJ, Gregor RJ. The effects of sloped surfaces on locomotion: a kinematic and kinetic analysis. J Biomech. 2006;39(9):1621-28.

[4] Mcintosh AS, Beatty KT, Dwan LN, et al. Gait dynamics on an inclined walkway. J Biomech. 2006;39(13): 2491-502.

[5] McVay EJ, Redfern MS. Rampway safety: foot forces as a function of rampway angle. Am Ind Hyg Assoc J. 1994;55(7):626-34

[6] Ebbeling CJ, Hamill J, Crussemeyer JA. Lower extremity mechanics and energy cost of walking in high-heeled shoes. J Orthop Sports Phys Ther. 1994;19(4):190-6.

[7] Kim S, Won M, Lee M. Balance Adjustments of Gait Pattern to Prevent Slip and Fall. The Korean Journal of Physical Education. 2001;40(2):821-31.

[8] Dixon PC, Pearsall DJ. Gait dynamics on a cross-slope walking surface. J Appl Biomech. 2010;26(1):17-25.

[9] Lee E, Choi J. The Effect of the Functional Insole during Stair Climbing of Elderly Women. Journal of Sport and Leisure Studies. 2011;46(1):921-30.

[10] Jin-Tae Han PT M, Jeoung-Sun cho PT M. The Spatio-temporal Analysis of Gait Characteristics during Ramp Ascent and Descent at Different Inclinations. J Kor Phys Ther. 2006;18(1):95-106.

[11] Han J-T, HwangBo G. Kinematic analysis of lower extremities during stairs and ramp climbing with older adults. Korean Journal of Sport Biomechanics. 2009 ;19(3):435-48.

[12] Perry J, Davids JR. Gait analysis: normal and pathological function. J Pediatr Orthop. 1992;12(6):815.

[13] Kawamura K, Tokuhiro A, Takechi H. Gait analysis of slope walking: a study on step length, stride width, time factors and deviation in the center of pressure. Acta Med Okayama. 1991;45(3):179-84.

[14] Craik RL, Dutterer L. Spatial and temporal characteristics of foot fall patterns. Gait Analysis: Theory and Application. St Louis, Mo: Mosby-Year Book. 1995: 143-58.

[15] Hof A, Elzinga H, Grimmius W, et al. Speed dependence of averaged EMG profiles in walking. Gait Posture. 2002;16(1):78-86.

[16] Hyun S. A Kinetic Comparison of Characteristics According to The Shoe's Heel Heights and Ground Conditions During Gait in Women. Unpublished Doctor's Degree. Jeju University. 2015.

[17] Sussman R, D'Amico J. The influence of the height of the heel on the first metatarsophalangeal joint. J Am Podiatry Assoc. 1984;74(10):504-8.

[18] Ryew Che Cheong, Hyeon Seung Hyeon. Kinetic Comparison of the Gait Pattern by Body Weights and Shoe's Heel Heights in the 20's Age Women. Journal of Sport and Leisure Studies. 2013;51(13):563-75.

[19] Eun S, Lee K, Seo J. The study on the gait pattern in stair-ascent activity of elderly persons. J Sport Leis Stud. 2004;22(22):511-22. 